\title{
Evaluation of Ecological Livable Construction in Guangzhou
}

\author{
Xin Qing ${ }^{1}$, Haifa Jia ${ }^{1,2, a}$ and Chengkui Liu $^{3,4}$ \\ ${ }^{1}$ College of Civil Engineering, Qinghai University, Xining, Qinghai, 810016, China \\ ${ }^{2}$ Qinghai Provincial Key Laboratory of Energy-saving Building Materials and Engineering Safety, Xining, Qinghai, 810016, China \\ ${ }^{3}$ Qinghai Building and Materials Research Co., Ltd Xining Qinghai 810016, China \\ ${ }^{4}$ The Key Lab of Plateau Building and Eco-community in Qinghai, Xining Qinghai 810016, China
}

\begin{abstract}
Guangzhou is the capital city of Guangdong Province, which is currently in a stage of transformation and development. This paper takes Guangzhou's ecological economy, ecological society, ecological environment as the research objects and constructs an evaluation index system for Guangzhou's ecological liveability. It takes social progress, economic development and environmental protection as the primary indicators. The index system is used to construct the ecological livability evaluation index system of Guangzhou through the entropy method.
\end{abstract}

\section{Introduction}

As China enters a new era of ecological civilization, under the background of striving to build a well-off society in an all-round way, people's thinking is gradually improving, which makes the people have new ideas about life and housing. Their awareness begins to change. In addition, research on the evaluation of ecologically livable construction has attracted widespread attention in many fields of the academic community has achieved fruitful research results.

\section{Overview of the study area, research methods and data sources}

Guangzhou is the capital of Guangdong Province, a subprovincial city. Guangzhou's geographical position is superior, it is the country's logistics hub and the hub city of China's the Belt and Road. Guangzhou is rich in natural resources and has a high economic status.

The research methods are Entropy method and Coupling coordination degree model, and the data comes from this article. The data comes from the "Guangzhou Statistical Yearbook", "Guangdong Statistical Yearbook" and "China Statistical Yearbook". The serial year is 2020-
$2018^{[1-3]}$.

\section{Construction and comprehensive evaluation of ecological livability evaluation index system}

\subsection{Principles of Index System Construction}

The construction of ecological livability evaluation indicators in Guangzhou needs to meet the principles of comprehensiveness, maneuverability, goal, orientation, dynamics and regionality.

(1) The principle of comprehensiveness; (2) The principle of operability; (3) Objective principle; (4) The guiding principle; (5) Dynamic principle; (6) The principle of regionality. ${ }^{[4-5]}$

\subsection{Construction of indicator system}

According to the entropy method, the weights of each index are assigned and comprehensively measured. The results are shown in Table 1 and Table 2. Table 1 is the evaluation system of ecological livability indicators in Guangzhou, and Table 2 is the comprehensive measurement score table of Guangzhou from 2010 to 2018.

Table 1. Evaluation System of Ecological Livability Indexes in Guangzhou

\begin{tabular}{|c|c|c|c|c|}
\hline First level indicator & Index explanation & Secondary indicators & Weights & $\begin{array}{l}\text { Indicator } \\
\text { attributes }\end{array}$ \\
\hline \multirow{4}{*}{ Social progress system } & \multirow{2}{*}{ population } & Total population (people) & 0.037188 & Positive \\
\hline & & Natural population growth rate (\%) & 0.039902 & Positive \\
\hline & \multirow{2}{*}{ Number of colleges } & Number of graduates (person) & 0.025230 & Positive \\
\hline & & Number of college graduates (person) & 0.032502 & Positive \\
\hline
\end{tabular}

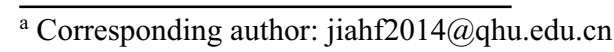




\begin{tabular}{|c|c|c|c|c|}
\hline & \multirow{2}{*}{ Road paving } & Paved road area (ten thousand square meters) & 0.028751 & Positive \\
\hline & & Length of paved road $(\mathrm{km})$ & 0.028751 & Positive \\
\hline & \multirow{3}{*}{ Resident consumption } & Disposable income of urban residents (yuan) & 0.028734 & Positive \\
\hline & & Engel coefficient of urban residents (\%) & 0.039020 & Negative \\
\hline & & Consumer Price Index (previous year $=100$ ) & 0.050739 & Negative \\
\hline \multirow{7}{*}{$\begin{array}{l}\text { Economic development } \\
\text { system }\end{array}$} & \multirow{2}{*}{ GDP } & GDP (100 million yuan) & 0.028498 & Positive \\
\hline & & GDP growth rate (\%) & 0.017578 & Positive \\
\hline & \multirow{2}{*}{ output value } & Total industrial output value (ten thousand yuan) & 0.028643 & Positive \\
\hline & & Proportion of tertiary industry (\%) & 0.031307 & Positive \\
\hline & \multirow{2}{*}{$\begin{array}{l}\text { Fiscal revenue and } \\
\text { expenditure }\end{array}$} & Financial revenue (ten thousand yuan) & 0.033478 & Positive \\
\hline & & Financial expenditure (ten thousand yuan) & 0.032598 & Positive \\
\hline & Unit energy consumption & $\begin{array}{l}\text { Energy consumption per unit of GDP (ton standard coal/10,000 } \\
\text { yuan) }\end{array}$ & 0.050477 & Negative \\
\hline \multirow{13}{*}{$\begin{array}{l}\text { Environmental } \\
\text { protection system }\end{array}$} & \multirow{8}{*}{ Greening quality } & Green coverage area (hectares) & 0.024938 & Positive \\
\hline & & Green coverage rate in built-up area (\%) & 0.035845 & Positive \\
\hline & & Green area (hectare) & 0.044494 & Positive \\
\hline & & Green space rate in built-up area (\%) & 0.039266 & Positive \\
\hline & & Park green area (hectare) & 0.068668 & Positive \\
\hline & & Park green area per capita (square meters) & 0.021969 & Positive \\
\hline & & Number of parks (a) & 0.034063 & Positive \\
\hline & & Park area (hectare) & 0.024298 & Positive \\
\hline & \multirow{2}{*}{ Waste disposal } & Urban sewage treatment rate & 0.021123 & Positive \\
\hline & & Industrial solid waste (tons) & 0.052147 & Negative \\
\hline & \multirow{3}{*}{ air quality } & Average value of sulfur dioxide in the air $(\mu \mathrm{g} / \mathrm{m} 3)$ & 0.041800 & Negative \\
\hline & & Average value of carbon monoxide in the air $\left(\mathrm{mg} / \mathrm{m}^{3}\right)$ & 0.038148 & Negative \\
\hline & & Turbidity (mg/L) & 0.019845 & Negative \\
\hline
\end{tabular}

\subsection{Comprehensive evaluation}

According to Table 2 and Figure 7, during the period 2010-
2018, the overall score of Guangzhou City was on the rise. Only in 2011-2012 and 2013-2014, there was a slight downward trend. The rising stage indicates that the overall ecological livability of Guangzhou is continuously improving.

Table 2. Qinghai Province 2010-2018 Comprehensive Measurement Score

\begin{tabular}{lccccccccc}
\hline Year & $\mathbf{2 0 1 0}$ & $\mathbf{2 0 1 1}$ & $\mathbf{2 0 1 2}$ & $\mathbf{2 0 1 3}$ & $\mathbf{2 0 1 4}$ & $\mathbf{2 0 1 5}$ & $\mathbf{2 0 1 6}$ & $\mathbf{2 0 1 7}$ & $\mathbf{2 0 1 8}$ \\
& & & & & & & & \\
\hline score & 0.026230 & 0.088731 & 0.077447 & 0.116417 & 0.095722 & 0.107862 & 0.131821 & 0.157532 & 0.198237 \\
\hline
\end{tabular}




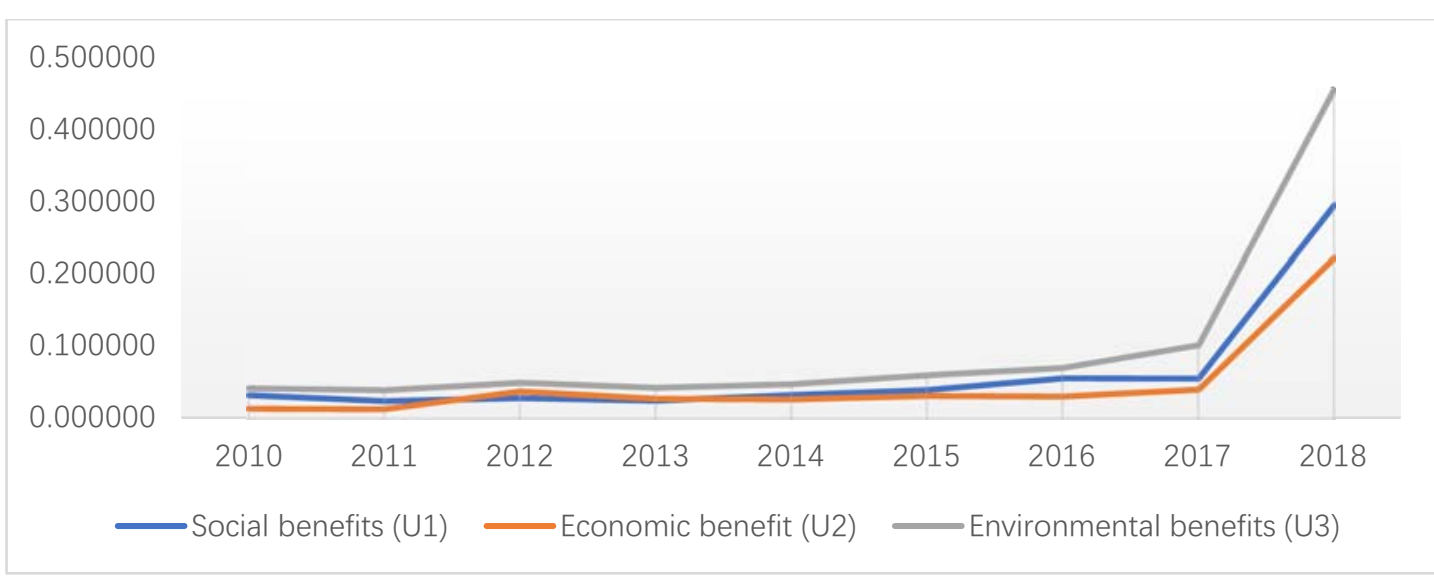

Figure 1. Changes in benefit evaluation scores of Guangzhou from 2010 to 2018

It can be seen from Table 2 and Figure 1 that during the period 2010-2018, both social benefits (U1), economic benefits (U2) and environmental benefits (U3) are on an overall upward trend. Among them, U3 is higher thanU1, higher than U2. During 2017-2018, U1, U2 and U3 increased the most, indicating that during 2017-2018, Guangzhou's social progress, economic development, environmental protection, and other policy measures have been put in place.

\subsection{Coupling and coordination analysis}

Based on the analysis of the coupling coordination degree, the SPASSAU is used to analyze the coordination degree of the scores of the established Guangzhou ecological livability evaluation index system. The analysis results are shown in Table 3 and Figure 2:

Table 3. Calculation results of coupling coordination degree

\begin{tabular}{|c|c|c|c|c|c|}
\hline Year & Coupling degree $\mathrm{C}$ value & Coordination index $\mathrm{T}$ value & $\begin{array}{l}\text { Coupling coordination degree } \\
\text { D value }\end{array}$ & Coordination level & Coupling degree \\
\hline 2010 & 0.905 & 0.03 & 0.164 & 2 & \multirow{5}{*}{ Serious disorder } \\
\hline 2011 & 0.908 & 0.026 & 0.153 & 2 & \\
\hline 2012 & 0.974 & 0.039 & 0.194 & 2 & \\
\hline 2013 & 0.972 & 0.032 & 0.176 & 2 & \\
\hline 2014 & 0.971 & 0.036 & 0.187 & 2 & \\
\hline 2015 & 0.964 & 0.044 & 0.206 & 3 & \multirow{3}{*}{ Moderate Disorder } \\
\hline 2016 & 0.946 & 0.053 & 0.223 & 3 & \\
\hline 2017 & 0.927 & 0.066 & 0.247 & 3 & \\
\hline 2018 & 0.957 & 0.325 & 0.557 & 6 & Barely coordinated \\
\hline
\end{tabular}

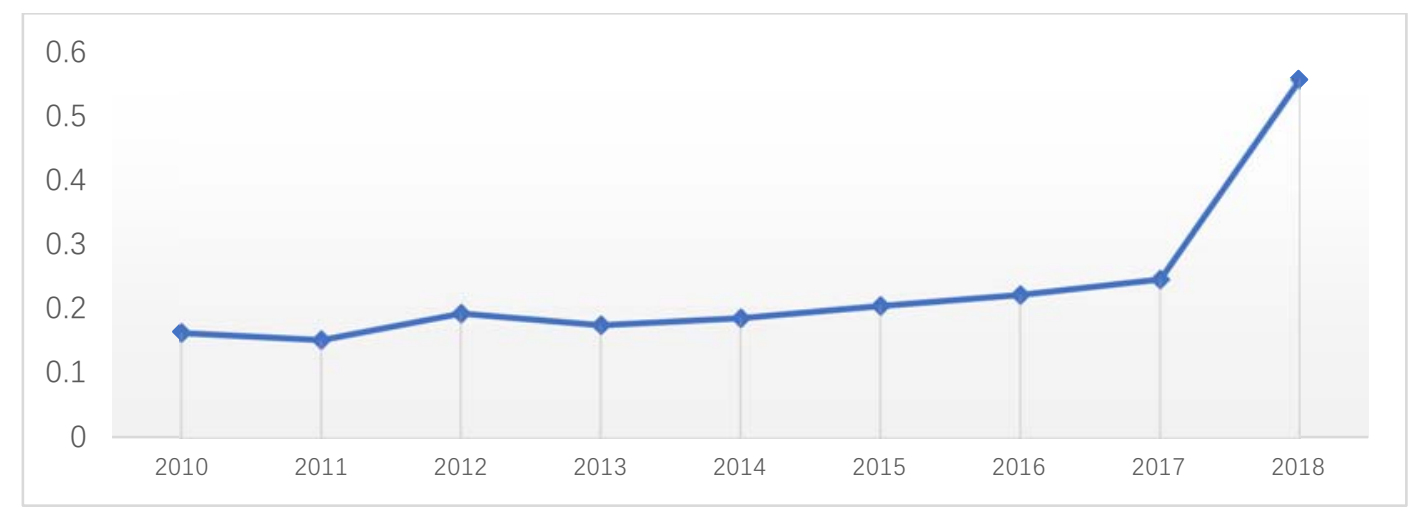

Figure 2. Analysis of coupling coordination degree from 2010 to 2018

It can be seen from the results of the coupling coordination degree analysis that the coordination degree of social benefits, economic benefits, and environmental benefits of Guangzhou from 2010 to 2018 has become increasingly coordinated.

\section{Conclusion}

In the evaluation index system of ecological livability in Guangzhou, it can be seen that the development direction of ecological livability in Guangzhou should focus on 
environmental protection. On this basis, develop the economy to ensure the construction of a livable city in Guangzhou.

\section{Acknowledgments}

This work was financially supported by the Open Fund Project of Key Lab of Plateau Building and Ecocommunity in Qinghai (Serial number: KLKF-2019-005), Qinghai Province Innovation Service Platform Construction Project (Serial number: 2018-ZJ-T01).

\section{References}

1. "2008-2019 Guangzhou Statistical Yearbook", Guangzhou Bureau of Statistics

2. "China Statistical Yearbook (2008-2018)", National Bureau of Statistics

3. "The Belt and Road" roadmap: Guangzhou's hub status is highlighted. People's Daily Online [reference date 2018-02-25]

4. Shan Hongcui, Sheng Dong, $\mathrm{Xu}$ Xingyi. Construction of the evaluation index system of water ecological civilization in Hunan Province based on cluster analysis and analytic hierarchy process $[\mathrm{J}]$. Water Resources Development and Management,2020(01):2-8.

5. Qi Yue, Zhao Chenhui, Liao Kezhi, Wang Zhihao. Construction and demonstration of evaluation index system of ecological civilization[J].Statistics and Decision-making,2018,34(24):60-63. 